\title{
"IVGI Noise App": An App to Raise Awareness of Noise Pollution and to Promote Spatial Technologies in Secondary Schools
}

\author{
Hans-Jörg Stark, Daria Hollenstein, Kevin Hürbi and Thomas Gerzner \\ ${ }^{1}$ IVGI FHNW, Muttenz/Switzerland·hansjoerg.stark@fhnw.ch
}

Short paper

\begin{abstract}
Over the past year, members of the Institute of Geomatics Engineering (IVGI) at the University of Applied Sciences and Arts Northwestern Switzerland (FHNW) have developed the "IVGI Noise App", an application to map and view noise level data. The web application is for use in environmental education during events, promoting science and engineering at secondary schools. The idea is to raise awareness of noise pollution and its consequences among students, while fostering their interest in spatial technologies by highlighting their role and potential in real-world problem solving.
\end{abstract}

\section{Background}

Noise pollution is a widespread environmental problem, particularly in urban areas (WHO 2011, BAFU 2011). Noise can be a nuisance and extended exposure to environmental noise can have serious adverse effects on human health (PASSCHIER-VERMEER \& PASSCHIER 2000, WHO 2011). In Switzerland, the Federal Office for the Environment (BAFU 2014a) estimates that every fifth person is affected by harmful or disturbing road traffic noise during the day, and every sixth person during the night. While top-down abatement measures are not yet fully implemented, or do not sufficiently protect people from health hazardous noise pollution (BAFU 2014b), environmental education may help build personal responsibility in prevention. In the case of road traffic noise pollution, raising awareness and spreading information about abatement is important, as individual decisions may contribute to mitigation, as for example through the use of quieter cars and tires, by driving at lower speeds, or using public transportation. There are indications that participatory noise sensing and mapping lead to increased awareness of environmental noise pollution (BECKER et al. 2013). The "IVGI Noise App" is used for participatory noise mapping on TecDays at secondary schools. The aim is to increase awareness of environmental noise and to highlight the role that spatial technologies play in noise level assessment and abatement implementation. TecDays are an initiative under the direction of the Swiss Academy of Engineering SATW to foster interest in science and engineering among secondary school students. On a TecDay, members of universities and the engineering industries visit a school and present a current real-world topic from their field. The idea is to teach science and engineering in a comprehensible manner and to illustrate their importance in present day problem solving in almost any field.

GI_Forum - Journal for Geographic Information Science, 1-2015.

(c) Herbert Wichmann Verlag, VDE VERLAG GMBH, Berlin/Offenbach. ISBN 978-3-87907-558-4.

(C) ÖAW Verlag, Wien. ISSN 2308-1708, doi:10.1553/giscience2015s345. 


\section{IVGI Noise App}

The 'IVGI Noise App' is a browser-based application to map and view noise level data. It can be accessed via http://www.see--you.ch/decibel/. The application is built with opensource technologies and comprises two web-GIS components that mainly rely on the JavaScript Library Leaflet (AGAFONKIN et al. 2013) and a central PostgreSQL-PostGISserver database (The PostgreSQL Global Development Group 2013; PostGiS Project SteEring Committee 2012) (Fig. 1). The web-GIS components communicate with the server database via jQuery AJAX Methods (JQUERY FOUNDATION 2013). The first web-GIS component is to map decibel (dB) values. Values are mapped either through geolocation of the mobile device via HTML5 Geolocation API (WORLD WIDE WEB CONSORTIUM W3C 2013), or manually through interactive mapping. The second component is to view a heat map (GOLUB 2010) computed from the collected data on top of a standard map like OpenStreetMap or Google Satellite. To collect noise data, dB levels are measured through the microphone of the device by use of a dB meter app. For convenience, we recommend students to use the free $\mathrm{dB}$ meter apps 'Decibel $10^{\text {th }}$, for iOS (SKYPAW CO. 2014) and 'Sound Meter' for Android (ANDROID BOY 2010). It must be stressed, however, that reliably measuring $\mathrm{dB}$ levels requires more sophisticated apps (EMPA 2015).

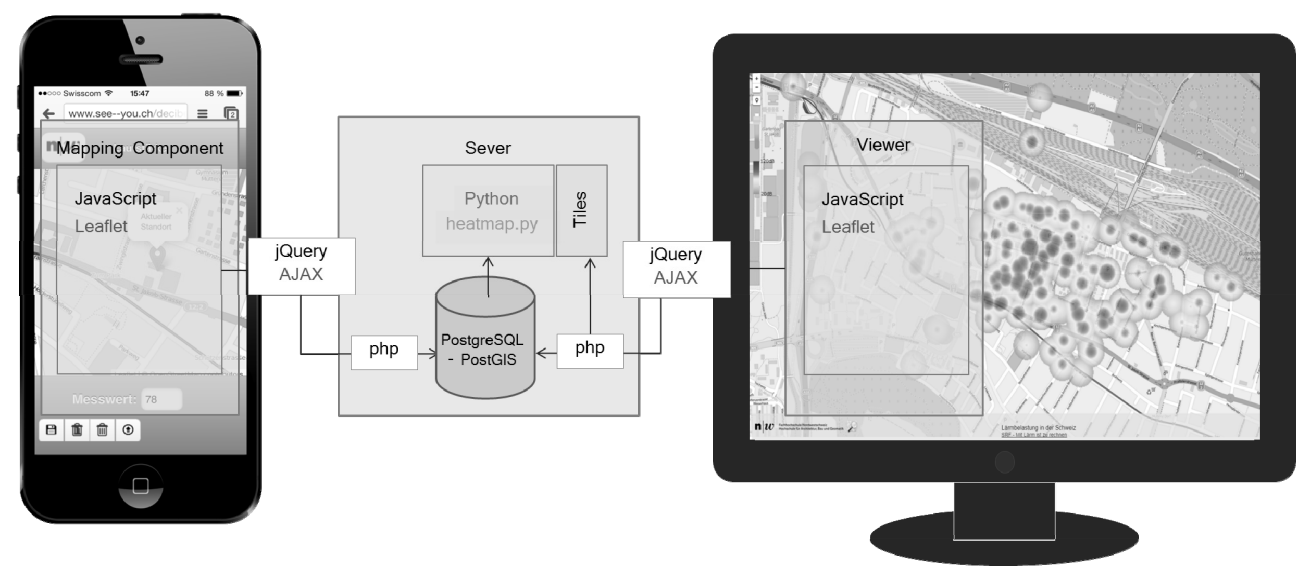

Fig. 1: Components and architecture of the „IVGI Noise App“, background map: OpenStreetMap (OPENSTREETMAP CONSTRIBUTORS 2015)

\section{Testing and Insights}

As part of the 90-minute TecDay lessons, the introduction to noise pollution, which includes estimating the $\mathrm{dB}$ level of audio samples, and the participatory noise mapping, are aimed at increasing awareness of environmental noise. The students survey the noise level around their school grounds with their smartphones and the 'IVGI Noise App' in groups of two, each group following a different track. Back in the classroom, the resulting heat map (Fig. 2 left) is discussed with respect to both noise sources and barriers visible on the map. Then, tools for strategic noise mapping in Switzerland are introduced (sonBASE, BAFU 
2011) to highlight the role of GIS in noise pollution assessment and the planning of abatement measures. Finally, students answer a questionnaire. This is an attempt to evaluate the lesson's effect on awareness of environmental noise pollution.

The testing completed so far comprises three TecDay events plus the use of the application during an introductory GIS course at the IVGI. The experience gained has led to adjustments in the structuring of the lesson and to more explicit surveying guidelines for students. Guidelines concerning measuring intervals (every 10-15 m), measuring duration $(>15 \mathrm{~s}$ ), and the tracks which should be covered are essential for producing maps which allow for meaningful discussion. While the free $\mathrm{dB}$ meter apps meet the requirements for the present purpose, as the collected data sufficiently reflect the differences between relatively noisy and quieter areas, the lesson should broach the issue of their deficiencies.

The use of the questionnaire revealed that less than one third of the students $(8 / 30)$ had heard of noise pollution previous to the TecDay. Whereas two thirds of the students $(21 / 30)$ had already known that they could use their smartphone to record $\mathrm{dB}$ levels, only four had installed a dB meter app. After completing the lesson, about half the students (17/30) said they will probably use the $\mathrm{dB}$ meter app again and a quarter (7/30) the 'IVGI Noise App'. When asked what they thought about noise pollution, two thirds $(14 / 22)$ stated that they consider it a serious issue, whereas only one tenth $(2 / 22)$ thought the problem was more marginal (eight students did not answer this question).
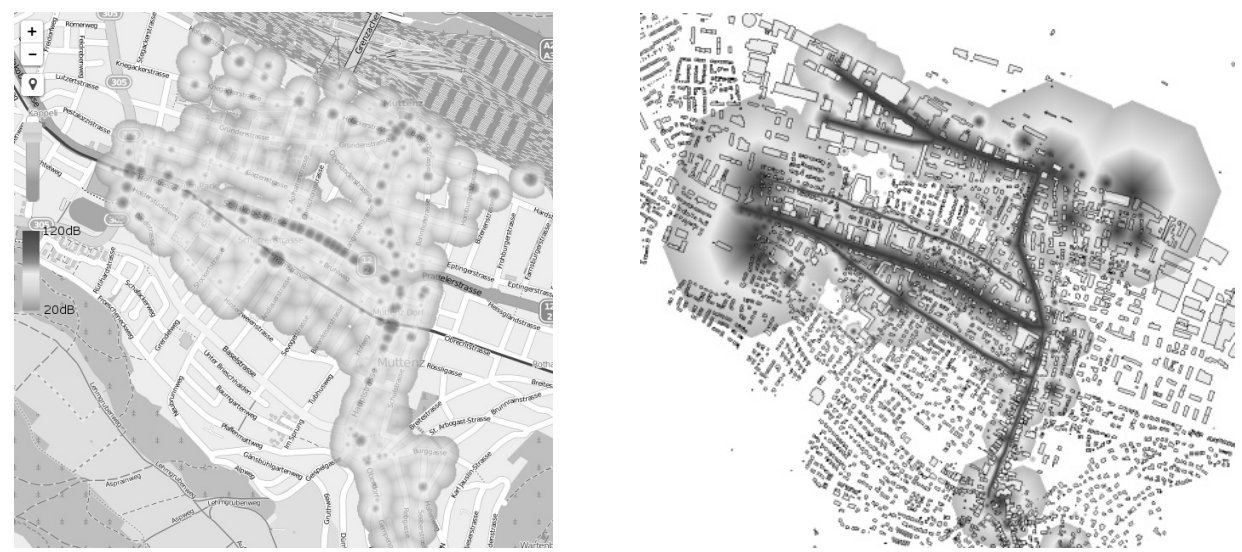

Fig. 2: Heat map from a survey conducted in Muttenz, Switzerland, background map: OpenStreetMap (2015) (left); Alternative data representation interpolated along streets (right)

There is room for improvement, however, where the promotion of engineering is concerned. More suitable representations of noise expansion computed ad-hoc from the surveyed point data may help to better illustrate links between noise occurrence, noise surveying and impact assessment through GIS analysis. Alternative data representations (Fig. 2) are being investigated and will hopefully be incorporated into the application over the current year. 


\section{References}

AGAFOnKIN et al. (2013), Leaflet 0.7.3. An Open-Source JavaScript Library for MobileFriendly Interactive Maps. http://leafletjs.com/ (Jan 2015).

ANDROID BOY (2014), Schallmessung: Sound Meter Version 1.6. https://play.google.com/store/apps/details?id=kr.sira.sound\&hl=de (Jan 2015).

BAFU (2011), Sehen wo Ihnen das Hören vergeht. sonBASE - die GIS-basierte Lärmdatenbank der Schweiz. Lärmbelastung flächendeckend ermitteln und analysieren. http://www.bafu.admin.ch/publikationen/publikation/01635/index.html?lang=de (22.01.2015).

BAFU (2014a), Lärmbelastung durch Strassenverkehr in der Schweiz. Zweite nationale Lärmberechnung, Stand 2012. www.bafu.admin.ch/uz-1406-d (22.01.2015).

BAFU (2014b), Massnahmen gegen Strassenlärm. http://www.bafu.admin.ch/laerm/10526/10527/10954/?lang=de (22.01.2015).

Becker, M., Caminiti, S., Fiorella, D., Francis, L., Gravino, P. et al. (2013), Awareness and Learning in Participatory Noise Sensing. PLoS ONE 8 (12), e81638. doi:10.1371/journal.pone.0081638.

EMPA (2015), Untersuchungsbericht Nr. 5'214'001'633 Update 2.2.2015. http://www.laerm.ch/dokumente/Smartphone+als+Schallpegelmesser.pdf (22.03.2015).

GoLUB, S. (2010), heatmap.py. http://sethoscope.net/heatmap (14.11.2014).

JQUERY FOUNDATION (2013), jQuery 1.10 AJAX Methods. http://api.jquery.com/jquery.ajax/ (28.01.2015).

OPENSTREETMAP CONTRIBUTERS (2015), OpenStreetMap. http://www.openstreetmap.org/ (28.01.2015).

PAsschier-Vermeer, W. \& PAsschier, W. F. (2000), Noise exposure and public health. Environmental Health Perspectives, 108 (Suppl. 1), 123-131.

PostGis Project Steering Commitee (2012), PostGiS 2.0.1 - Spatial and Geographic objects for PostgreSQL. http://postgis.net/2012/06/22/postgis-2-0-1 (28.01.2015).

SKYPAW CO. (2014), Decibel 10th: Pro Sound Meter Version 4.1.1. http://www.skypaw.com/apps/instadecibel/ (28.01.2015).

The PostgreSQL Global DeVelopment Group (2012), PostgreSQL 9.1.4. http://www.postgresql.org/ (28.01.2015).

World HEALTH ORganizATION (WHO) (2011), Burden of disease form environmental noise. Quantification of healthy life years lost in Europe. http://www.euro.who.int/_data/assets/pdf_file/0008/136466/e94888.pdf?ua=1 (14.01.2015).

World WIDE WEB CONSORTIUM (W3C) (2013), Geolocation API. http://www.w3.org/TR/geolocation-API/ (20.03.2015). 